\title{
Attaining a Beam-Like Behavior with FRP Strips and CAM Ribbons
}

\section{Elena Ferretti}

DICAM - Department of Civil, Chemical, Environmental, and Materials Engineering, Alma Mater Studiorum, Università di Bologna, Italy

\section{Abstract}

One of the major concerns in the seismic retrofitting of masonry walls is that of increasing the ultimate load for out-of-plane forces. In multi-story buildings, these forces may originate from the hammering actions of floors, when the earthquake direction is orthogonal to the wall. A possibility for counteracting the out-of-plane displacements is retaining the wall by building some buttresses, that is, some beams lean against the wall and disposed vertically. Another possibility is to make the buttress in the thickness of the wall. In this second case, we must cut the wall for its entire height, realize the buttress, and restore the masonry wall around it. In both cases, the interventions are highly invasive. The first intervention also leads to increments of mass that enhance the attraction of seismic forces. The aim of this paper is to find a less invasive and lighter alternative for realizing buttresses. We proposed to use FRP strips and steel ribbons in a combined fashion, so as to realize an ideal vertical I-beam embedded into the wall, without requiring to cut the masonry. We also provided some experimental results for verifying the effectiveness of the model.

Keywords: CAM system, masonry walls, seismic retrofitting, out-of-plane loading, hammering action.

\section{Introduction}

Unreinforced masonry (URM) bearing wall buildings show poor performance in earthquakes, mainly due to the inherent brittleness, lack of tensile strength, and lack of ductility. The regions that can generate strong earthquakes, but only rarely, may not have regulations limiting the construction of URMs. In those regions, there is particular cause for concern, especially if they experienced a high growth rate, leading to the uncontrolled construction of many URM buildings. As an example, just think that the lack of earthquake codes preventing the construction of URMs was a major factor in the high death toll in the 2010 Haiti earthquake. After the 1933 Long Beach earthquake, building codes changed prohibiting the construction of new URM buildings in California (Hess, 2008) and state law (enacted in 1986) required seismic 
retrofitting of existing structures. Some other communities then used the ordinances adopted in California since the early 1950's, for addressing the earthquake hazard of URM buildings, as a model.

Retrofits are generally intended to prevent injury and death to people, but not to protect the building itself. They are relatively expensive and may include tying building elements (such as roof, floors, and walls) to each other, starting from building foundation, so that the building moves as a single unit, thus attaining the so-called box-type behavior. The goal is insuring a coherent load path for lateral loads, reduction of out-of-plane wall failures, reduction of loss of support for floors and roofs, and reduction of falling parapets or ornamentation. In particular, one of the main concerns in seismic retrofitting of masonry buildings is avoiding the mechanisms of out-of-plane collapse that originate from the hammering action of floors (Figure 1).

Among the strengthening methods with horizontal and vertical ties, the active reinforcements are the most suitable for increasing strength, cracking behavior, and ductility of URMs, but suffer from some weak points due, essentially, to the fact of being local reinforcements. We can overcome many of these weak points (Ferretti, in prep. a) by using the CAM system, a continuous reinforcement technique with pretensioned ribbons passing through the thickness of the wall (Figure 2), which applies to both masonry (Dolce et al., 2001, 2008, 2009; Ferretti, in prep. b; Marnetto and Vari, 2015; Marnetto et al., 2014) and concrete (Ponzo et al., 2011) structures. In particular, the CAM system allows us to achieve the main target of a retrofitting intervention, that is, restoring the box-type behavior wherever it is lacking. Nevertheless, it shows a pathological sensitiveness to out-of-plane loadings, as the configuration of the three-dimensional net of the CAM system is labile along the transverse direction of the wall (Figure 3).
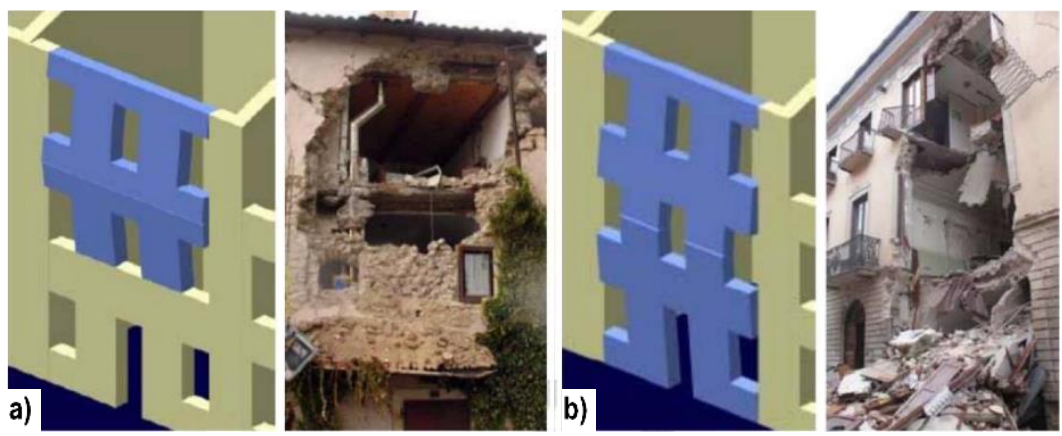

Figure 1. Mechanisms of out-of-plane collapse in presence of an upper kerb: a) partial mechanism; b) global mechanism. 


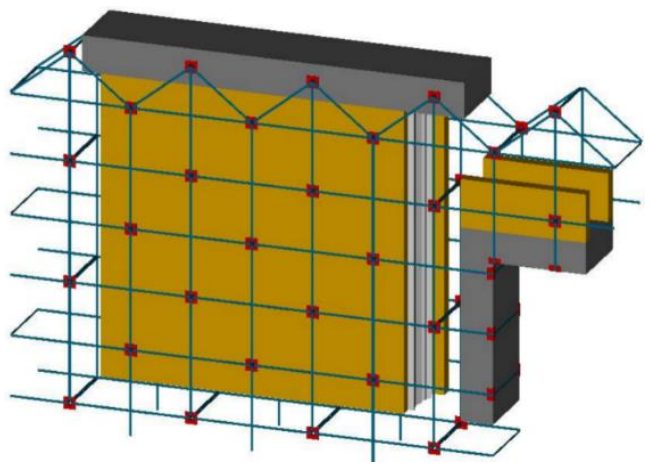

Figure 2. Connections established by the CAM system between a double layer vertical wall, the upper R/C kerb and a door (Dolce et al., 2001).

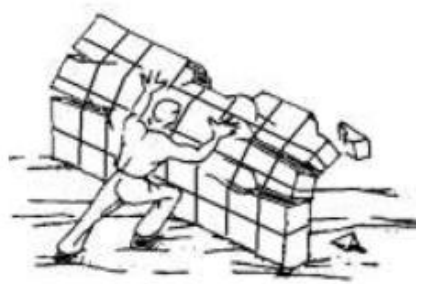

Figure 3. Sensitiveness of a wall reinforced with the CAM system to out-of-plane loading.

Consequently, the CAM system is not suitable for increasing the ultimate load of collapse when the directional properties of the earthquake involve a hammering action of floors on the walls. This does not affect the effectiveness of the CAM system, which remains a useful device of safeguarding life when the wall collapses (Ferretti, in prep. a). Anyway, the question we want to answer in this paper is whether it is possible to exploit the CAM system also for improving the out-of-plane performances of walls.

\section{A Proposal of Combined Technique for Improving the out-of-plane Performance of the CAM System}

When a vertical wall receives subsequent horizontal thrusts from a floor due to the oscillatory nature of the earthquake forces, we say that the floor exerts a hammering action on the wall. The subsequent pulses of the earthquake may then lead the wall to either overturn or break into two parts, in correspondence of the floor (Figure 4): this second failure mechanism, the most usual one, activates when an upper kerb retains the wall. As far as the meaning of symbols in Figure 4 is concerned:

- $\mathrm{s}$ is the thickness of the wall;

- $\mathrm{h}$ is the height of the wall;

- $\mathrm{W}$ is the self-weight of the wall; 
- $\mathrm{P}_{\mathrm{s}}$ is the weight transmitted to the wall by the floor;

- $\mathrm{N}$ is the weight of upper walls and floors;

- $\mathrm{F}_{\mathrm{V}}$ is the vertical component of the thrusts given to the wall by arches and vaults;

- $\mathrm{F}_{\mathrm{H}}$ is the horizontal component of the thrusts given to the wall by floors, arches, and vaults;

- $\quad a$ is the distance between $P_{s}$ and the hinge in $B$;

- $\mathrm{d}$ is the distance between $\mathrm{N}$ and the hinge in $\mathrm{B}$;

- $\mathrm{d}_{\mathrm{V}}$ is the distance between $\mathrm{F}_{\mathrm{V}}$ and the hinge in $\mathrm{B}$;

- $\mathrm{h}_{\mathrm{V}}$ is the distance between $\mathrm{F}_{\mathrm{H}}$ and the hinge in $\mathrm{B}$.

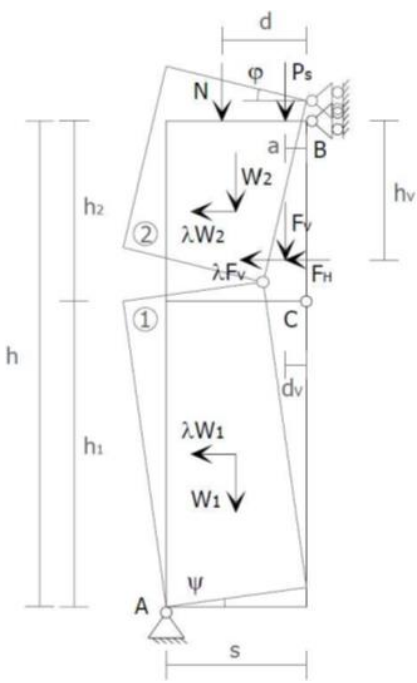

Figure 4. Scheme of the failure mechanism for hammering action of a floor, when an upper kerb retains the wall.

As we have previously discussed, the CAM system is not able to counteract failure mechanisms due to out-of-plane loadings. Thus, it is not able to counteract the hammering action of floors, in the sense that the ultimate load $\mathrm{F}_{\mathrm{H}}$ does not increase after the application of the CAM system. Therefore, for increasing the wall resistance to hammering actions we must combine the CAM system with other reinforcement techniques.

The idea underlying the retrofitting technique proposed in this paper is to use the CAM system not just in addition to something else, but in collaboration with another reinforcement system, in order to obtain a further strengthening mechanism, with characteristics different from those of both the CAM system and the second 
reinforcement system. In particular, we thought to exploit the transversal link provided by pre-tensioned CAM-like ribbons for establishing a stiffness constraint between vertical FRP strips applied on the two opposite faces of the wall.

The stiffness constraint is essential in modifying the mechanical behavior of the FRP reinforcement. In fact, before the application of the CAM system, the two strips of FRP work independently (Figure 5a). In particular, of the two strips only the one applied on the stretched face is effective in increasing the ultimate load of the wall under bending. Actually, the strip on the compressed face of a bent wall undergoes buckling and delaminates very soon. In other words, we apply two strips but, during an earthquake, the hammering action loads either one or the other, depending on the direction of the seismic forces. On the contrary, if we use some ribbons of the CAM net for tying together the two opposite strips (Figure 5b), we force both strips to work at the same time, as the ribbons prevent the buckling of the compressed strip. The higher the stiffness of the transversal link, the higher the collaboration between the two strips. In the ideal case of infinite stiffness of the transversal link, the two strips behave as the two flanges of an I-beam with very thin web (Figure $5 \mathrm{c}$ ).

a)

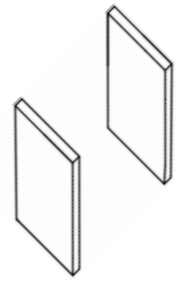

b)

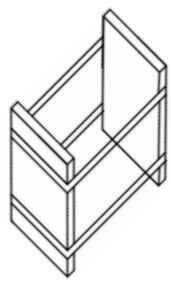

c)

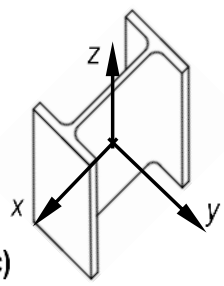

Figure 5. a) Two vertical strips of FRP applied on the opposite faces of the wall, without any bond between them (the wall is not represented); b) The two opposite strips of FRP are tied together by using some ribbons of the CAM net, which wraps the entire wall; c) Ideal I-beam beavior of the two strips when the stiffness of the ribbons is infinite.

The collaboration between the two strips improves the performance of the reinforcement system considerably: in Figure 5a, the moment of inertia of the reinforcement system, $I_{y}^{a}$, is provided by just the stretched strip:

$$
I_{y}^{a}=\frac{B b^{3}}{12}
$$

where $B$ is the width of the strip and $b$ is the thickness of the strip, while, in Figure $5 b$, it is provided by $I_{y}^{b}$, the moment of inertia of the two strips linked together, with a link length equal to the thickness of the wall, s. In the ideal case where the stiffness of ribbons is infinite (Figure 5c), the moment of inertia of the reinforcement system equals $I_{y}^{c}$, the moment of inertia of the I-beam with very thin web:

$$
I_{y}^{b}=I_{y}^{c}=2\left(\frac{B b^{3}}{12}+B b\left(\frac{s}{2}\right)^{2}\right) \text {. }
$$


Moreover, since the thickness of the strip is usually very small, the order of magnitude of the second term in Eq. (2) is greater than the order of magnitude of the first term. Therefore:

$$
\begin{gathered}
I_{y}^{c} \cong 2 B b\left(\frac{s}{2}\right)^{2} ; \\
I_{y}^{c} \gg I_{y}^{a} .
\end{gathered}
$$

In conclusion, the greater the stiffness of the ribbons, the greater the performance of the reinforcement system, which tends to behave as an ideal I-beam, embedded into the wall. Moreover, other things being equal, the greater the thickness of the wall, the greater the moment of inertia of the ideal I-beam (Eq. (3)).

\section{Experimental Verification of the Effectiveness of the Model}

In order to verify that, by tying FRP strips placed one in front of the other as shown in Figure 5b, the strips behave as flanges of an I-beam, we built, strengthened, and tested under bending load three brick walls of identical dimensions (Figure 6). The bricks we used are of the type Bolognese. They measure $24.5 \mathrm{~cm}$ in length, $11 \mathrm{~cm}$ in height, and $5.5 \mathrm{~cm}$ in depth (Figure 7). We cut out some of them in order to fit the dimensions of the finished wall (Figure 7d). Moreover, we drilled the bricks for the ribbons to pass through, before building the wall (Figure 7e).

We labeled and strengthened the three specimens as described below:

- Specimen P1: we built a drilled wall according to the quincunx scheme (Figure 8) and applied two nets of CAM-like steel ribbons, staggered along the horizontal and vertical direction. We pre-tensioned all the ribbons during their clamping, by means of a special tool.

- Specimen P2: we built an undrilled wall and applied two CFRP strips along the vertical centerlines, one strip for each face of the wall (Figure 9).

- Specimen P3: we built a drilled wall according to the quincunx scheme and applied both the staggered nets of CAM-like steel ribbons and the CFRP strips along the vertical centerlines, by using some ribbons of both threedimensional nets for tying the strips together (Figure 10). 

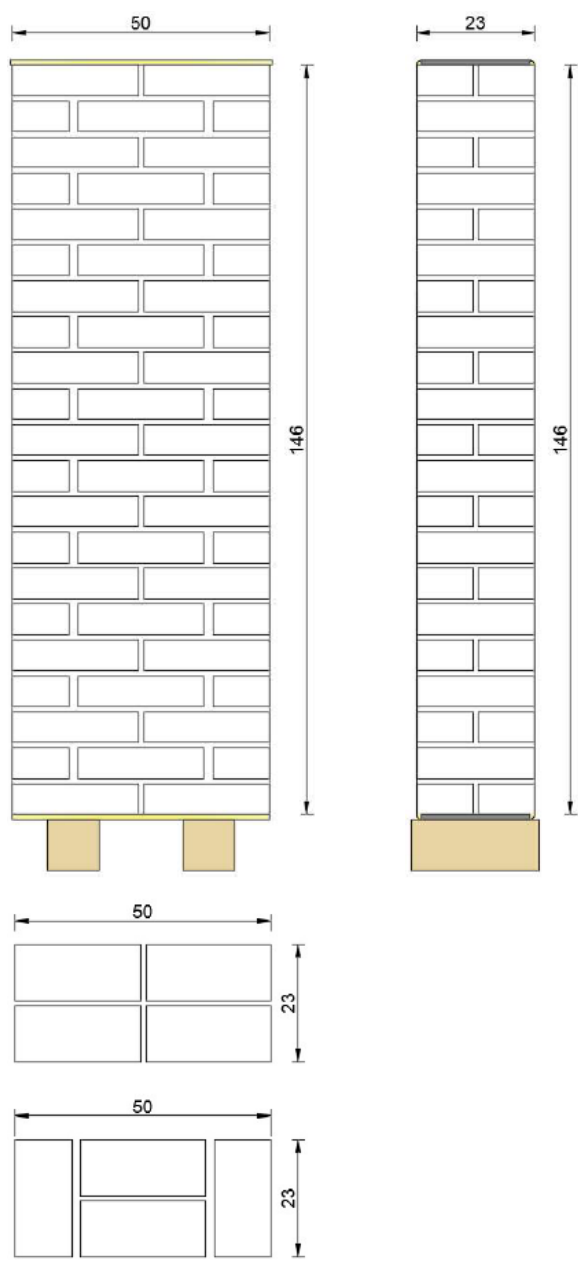

Figure 6. Dimensions of the finished masonry specimens.
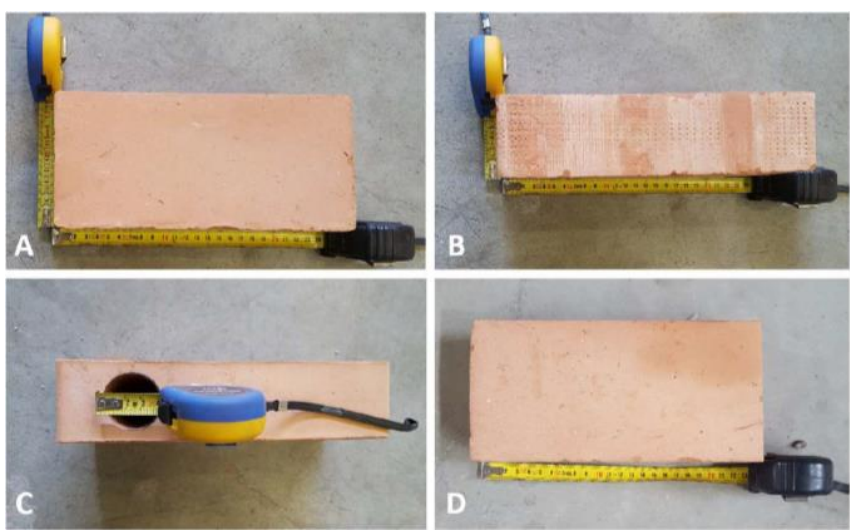

Figure 7. Bricks of the type Bolognese.

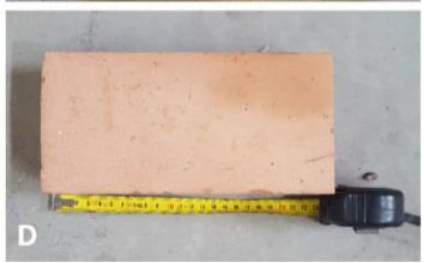


We instrumented the three specimens with strain-gauges on both faces (Figures 810). Moreover, we used some LVDTs for measuring the displacements of the middle points on both faces and the displacements of the ends. We tested the three specimens in horizontal configuration (Figure 11), by performing bending tests in displacement control.

Figure 12 shows the load/displacement diagram for the bending test of the specimen P1. The first peak of load (first positive peak) corresponds to the separation into two parts of the specimen for crack propagation in Mode I (Ferretti, 2004a, 2004b, 2004c, 2009, 2013; Ferretti and Di Leo, 2008; Ferretti et al. 2003), with disconnection between central bricks and mortar and formation of the upper hinge under the loading piston (Figure 11). Since the crack propagation in Mode I is very brittle (Ferretti, 2004c), the central crack that activated for the first positive peak extended to the entire thickness rapidly. If there had not been the ribbons, this would have led the wall to collapse.
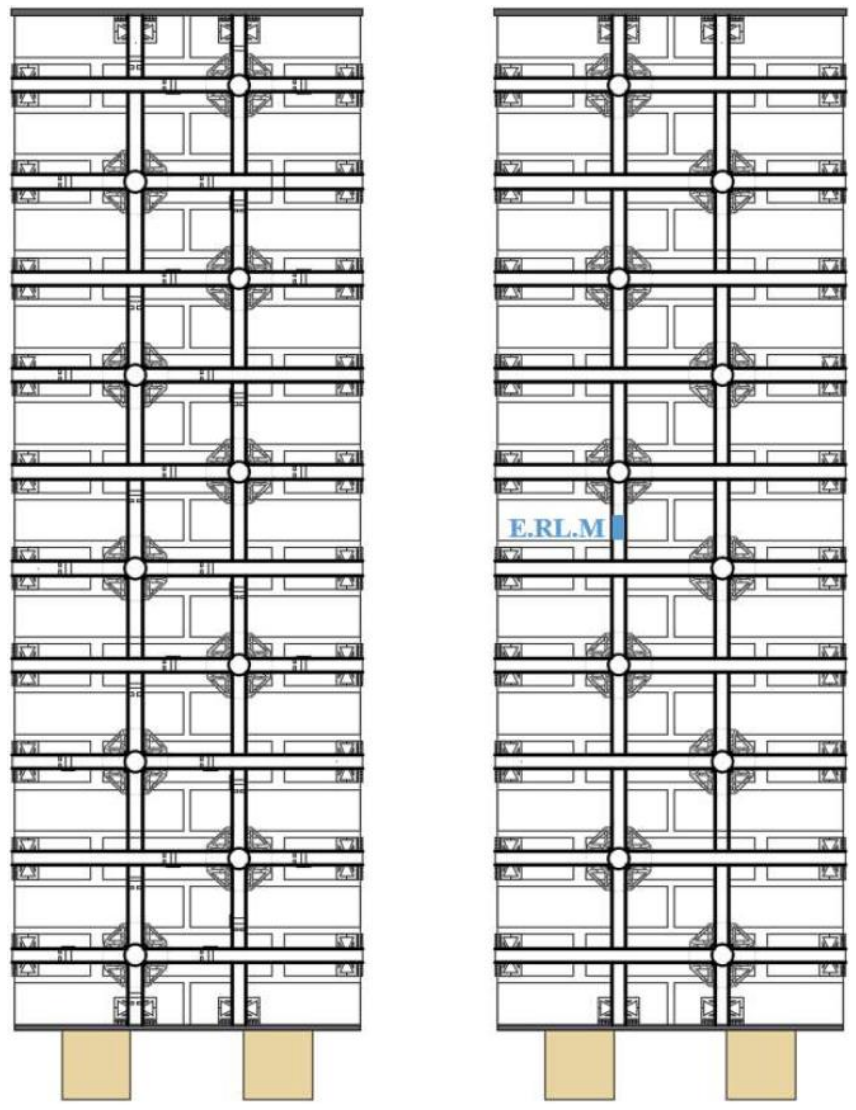

Figure 8. Instrumentation of specimen P1 with strain-gauges: compressed face on the left and stretched face on the right. 

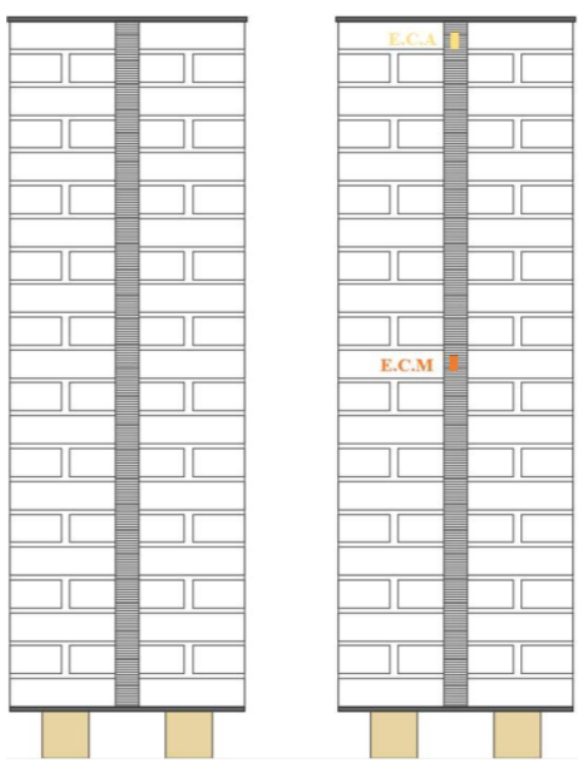

Figure 9. Instrumentation of specimen P2 with strain-gauges: compressed face on the left and stretched face on the right.
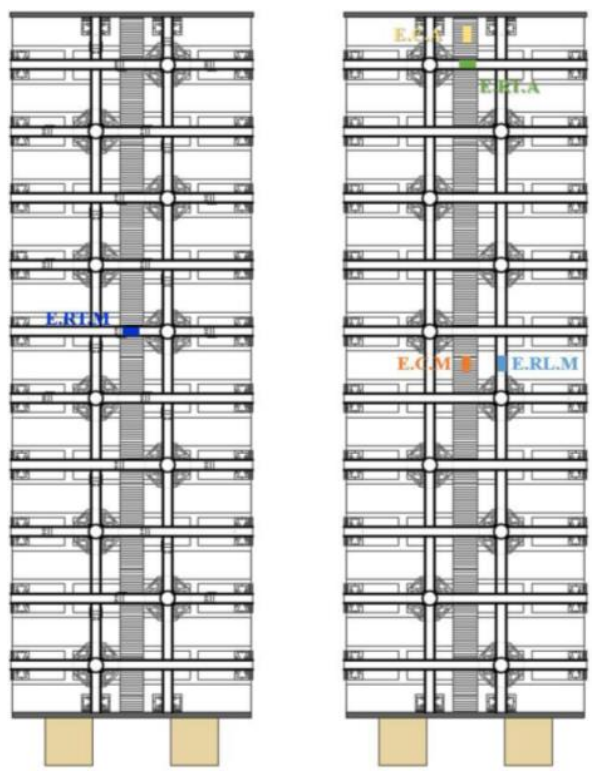

Figure 10. Instrumentation of specimen P3 with strain-gauges: compressed face on the left and stretched face on the right. 

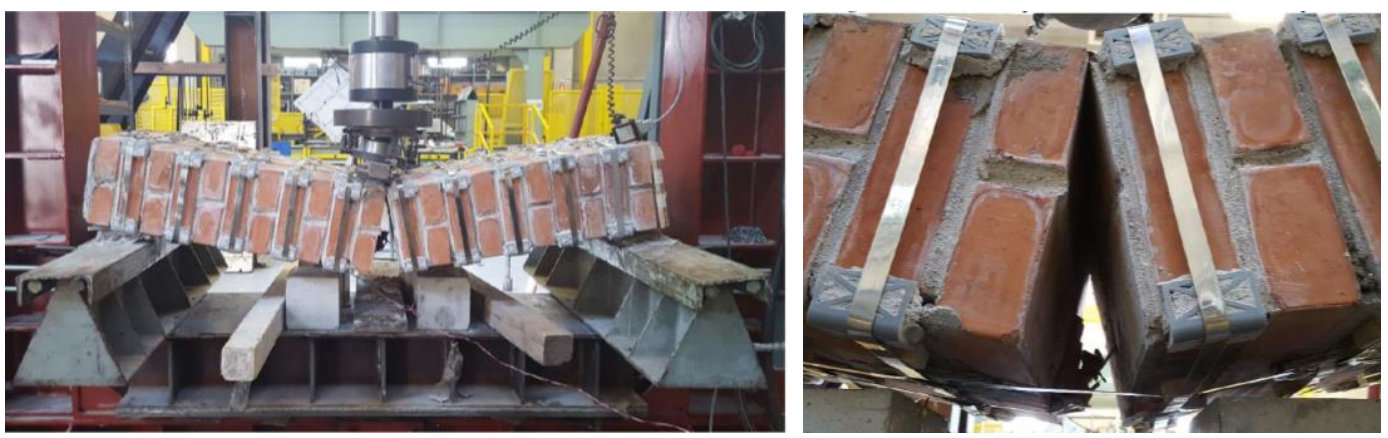

Figure 11. Deformation of the specimen P1 during bending test: zoom of the central part on the right.

On the contrary, the ductility of the reinforcement system allowed the wall to continue bearing load even after crack opening. Actually, at first the load decreased to near-zero values (first negative peak in Figure 12), but, since the ribbons prevented the wall from collapsing, the wall then could bear further increments of load. The second ascending branch of the load/displacement diagram is still almost linear until the second positive peak, but with a decreased slope. This means that the system has become more deformable.

After the second positive peak, the stiffness of the system decreased further, due to the yielding of the ribbons and the slippages in the clamps. This phase was very long and led to great vertical displacements (Figure 12) and large opening of the central crack (Figure 11), but without collapse. In particular, the high deformability without collapse of the specimen P1 is evident in the shot of Figure 11, where the lower faces of the specimen have almost reached the two concrete cubes, positioned underneath the specimen for avoiding the crushing of the LVDTs in case of wall collapse. It is also worth noting how the lower ribbons of the central part, though highly deformed, still prevent the rigid rotation around the hinge even after a large crack opening has occurred. We may then conclude that, once they exhausted the strengthening function (with the crack opening), the steel ribbons find a second use and start working as a device of safeguarding life. 


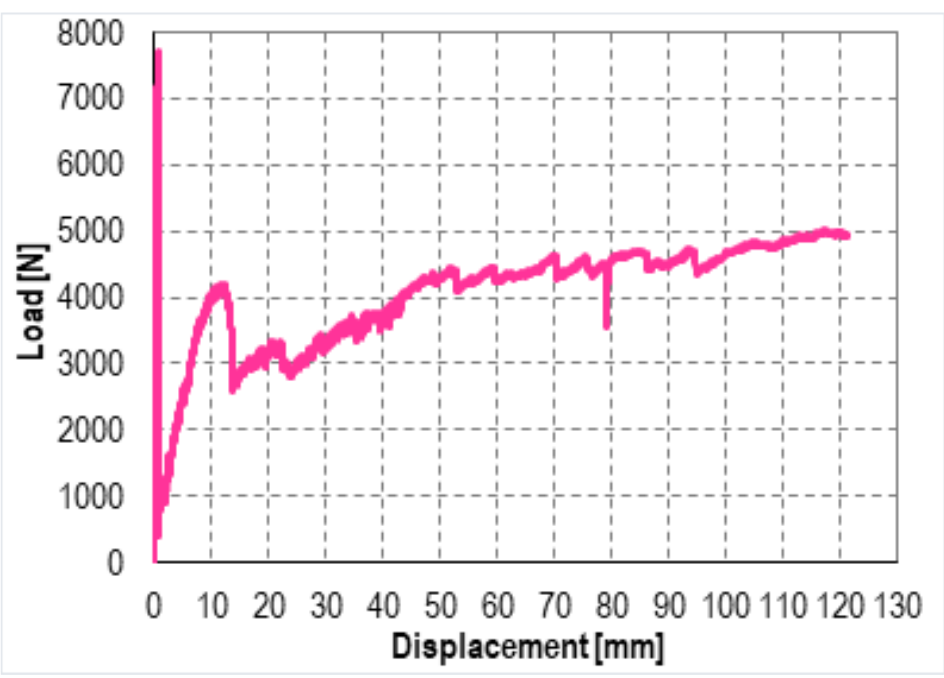

Figure 12. Load/displacement diagram for the specimen P1.

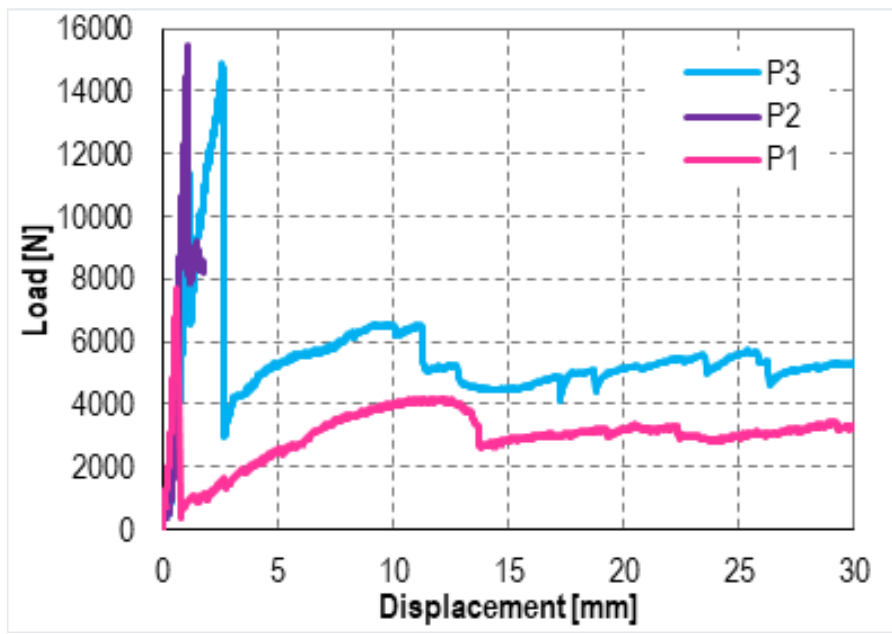

Figure 13. Load/displacement diagrams of the three specimens: displacement field truncated at the value of $30 \mathrm{~mm}$.

In Figure 13, we plotted the load/displacement diagrams of the three specimens, by truncating the horizontal axis for a value of vertical displacement equal to $30 \mathrm{~mm}$. The truncation allows us to compare the initial stiffness, which is almost the same for the three specimens. Moreover:

- The load/displacement diagram for the specimen P2 is almost linear until the maximum load, which is twice the maximum load of the specimen P1. Then, the load decreases because the stretched strip delaminates and the wall collapses rapidly: this failure mechanism is very brittle. 
- The load/displacement diagram for the specimen P3 exhibits a maximum load that is almost equal to the maximum load of the specimen P2. This means that the hinge forms when the load equals the delamination load of the stretched CFRP strip, as for the specimen P2. Nevertheless, from this moment forth, the resistance mechanism of the wall modifies due to the action of the steel ribbons and the system starts to benefit of the combined reinforcement system: the steel ribbons retain the delaminated strip, which forms an I-beam with the compressed strip. Due to the high deformability of the ribbons, the constraint established between the two CFRP strips is not rigid, but deformable. Anyway, the deformable I-beam allows the wall to continue bearing load with values of load greater than those of the specimen P1. This means that the wall can continue to benefit of the strengthening properties of the CFRP strips even after strip delamination, although only in part. Moreover, the retaining action of the ribbons modifies the failure mechanism, which ceases to be brittle and become ductile.

\section{Conclusions}

For improving the performance of walls under out-of-plane loads, we proposed to combine a continuous three-dimensional reinforcement system of steel ribbons with FRP strips, applied on both sides of the wall, one in front of the other.

The proposed combination is indeed a mechanical coupling, as we used some steel ribbons of the three-dimensional net for tying the strips together. It is exactly the mechanical coupling to provide us with the main advantages of the combined technique. Actually, due to the mechanical coupling, the combined technique is not simply the result of using two reinforcement techniques together, but something different from both constituent reinforcement systems. In particular, two facing FRP strips cease to behave as independent reinforcements and become parts of the same reinforcement element, which is an ideal vertical I-beam. As this increases the moment of inertia of the reinforcement element considerably, the incremental strength given by the ideal I-beam is much greater than the incremental strength given by the strips taken singularly. The ideal vertical I-beam will then counteract the out-of-plane displacements caused by hammering actions, specifically of the floors.

Therefore, tying the vertical FRP strips by means of steel ribbons has the same effect as to cut the masonry wall for embedding an FRP I-beam into the wall, as a buttress. The main advantage of using steel ribbons and FRP strips instead of cutting the wall and embedding an FRP I-beam is that drilling the wall in some specific positions is much less invasive than cutting the wall for its entire height. Moreover, restoring the masonry texture around the I-beam so as not to leave any cavities is not easy, from a technical point of view, while the installation of strips and ribbons is not particularly difficult. 
For verifying the actual possibility to attain an I-beam behavior by using strips and ribbons, we performed bending tests on three wall specimens, strengthened as follows: with CAM-like steel ribbons the first, with CFRP strips the second, with both CAM-like steel ribbons and CFRP strips the third. We found that the I-beam effect is appreciable just after the delamination load of the strips. In our tests, this effect does not led to increase the residual bearing capacity greatly, because we used just one ribbon per loop (it is possible to use up to 4 ribbons for loop). Therefore, this specific result is certainly ameliorable. Nevertheless, the performance of the third specimen is deeply satisfying for the following reasons:

- The combined technique inherits from the CFRP strips the ability of increasing the maximum out-of-plane load of the masonry wall (Figure 14). This is essential for improving the performance of the masonry wall when subjected to hammering actions, for example by the floors.

- The combined technique inherits from the three-dimensional reinforcement system with steel ribbons a high degree of ductility (Figure 14). In particular, the masonry wall is able to bear loads even after the hammering actions have cracked it. This is essential in the aim of safeguarding life.

- The combined technique takes advantage from the beam-like mechanism, which allows the FRP strips to work even after delamination, thus providing a residual bearing capacity, greater than that provided by the steel ribbons alone.

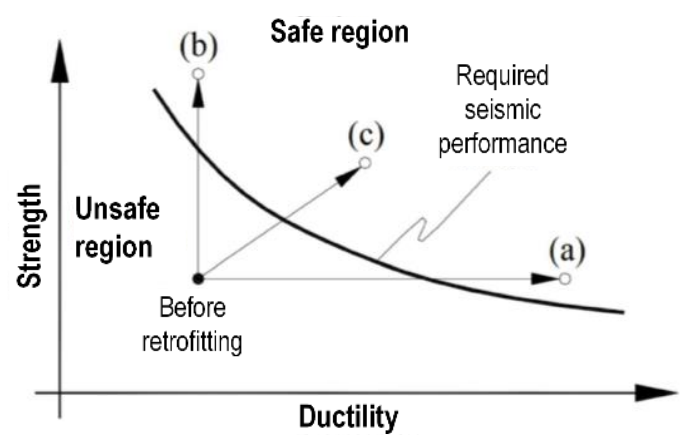

Figure 14. How the retrofitting systems allow an unsafe structure to reach the safe region for seismic loads: an FRP reinforcement increases strength but not ductility, leading the structure to the point (b) along the vertical path; the CAM system and, more in general, a three dimensional reinforcement with steel ribbons increases ductility but not strength, leading the structure to the point (a) along the horizontal path; the combined reinforcement increases both strength and ductility, leading the structure to the point (c).

It is worth noting that increasing just the strength or the ductility is a feature of not only FRP reinforcements and CAM-like systems: it is a limitation common to the most 
known traditional reinforcement techniques. The combined technique overcomes this limitation, allowing us to increase both.

\section{Further developments}

Our first bending tests have shown that coupling steel ribbons and CFRP strips mechanically can actually improve the out-of-plane behavior of masonry walls. In particular, we improved the post-delamination behavior, making it ductile, while we did not success in increasing the delamination load of the CFRP strips. The reason for this lies in the number of used steel ribbons, just one for each loop of the threedimensional net. It reasonable to expect that, by increasing the number of steel ribbons per loop, also the maximum bending load bearing by the wall will increase. In order to verify this last statement, we are currently undertaking a further experimental program on the combined technique (Ferretti, in prep. c).

\section{References}

[1] Dolce, M., Nigro, D., Ponzo, F. C., \& Marnetto, R. (2001). The CAM system for the retrofit of masonry structures. $7^{\text {th }}$ International Seminar on Seismic Isolation, Passive Energy Dissipation and Active Control of Vibrations of Structures, October 2-5, 2001, Assisi, Italy.

[2] Dolce, M., Ponzo, F. C., Di Croce, M., Moroni, C., Giordano, F., Nigro, D., \& Marnetto, R. (2009). Experimental assessment of the CAM and DIS-CAM systems for the seismic upgrading of monumental masonry buildings. Proceeding of $1^{\text {st }}$ international conference on protection of historical constructions, 2009, Rome, Italy, pp. 1021-1027.

[3] Dolce, M., Ponzo, F. C., Goretti, A., Moroni, C., Giordano, F., De Canio, G., \& Marnetto, R. (2008). 3d dynamic tests on 2/3 scale masonry buildings retrofitted with different systems. The $14^{\text {th }}$ World Conference on Earthquake Engineering, 12-17 October, 2008, Beijing, China.

[4] Ferretti, E. (in prep. a). Effectiveness of Active Confinement Techniques with Steel Ribbons: Masonry Buildings.

[5] Ferretti, E. (in prep. b). Some of the latest active strengthening techniques for masonry buildings: a critical analysis.

[6] Ferretti, E. (in prep. c). Combined Strengthening Techniques for Improving the out-of-Plane Performance of Masonry Walls.

[7] Ferretti, E. (2013). A Cell Method Stress Analysis in Thin Floor Tiles Subjected to Temperature Variation. CMES-Comp Model Eng, 36(3), pp. 293-322.

[8] Ferretti, E. (2009). Cell Method Analysis of Crack Propagation in Tensioned Concrete Plates. CMES-Comp Model Eng, 54(3), pp. 253-281.

[9] Ferretti, E. (2004a). Modeling of the Pullout Test through the Cell Method. Proceedings of the International Conference on Restoration, Recycling and Rejuvenation Technology for Engineering and Architecture Application, pp. 180-192. 
[10] Ferretti, E. (2004b). A Discrete Nonlocal Formulation using Local Constitutive Laws. Int J Fracture, 130(3), pp. L175-L182.

[11] Ferretti, E. (2004c). Crack-path analysis for brittle and non-brittle cracks: A cell method approach. CMES-Comp Model Eng, 6(3), pp. 227-244.

[12] Ferretti, E., \& Di Leo, A. (2008). Cracking and creep role in displacements at constant load: Concrete solids in compression. CMC-Comput Mater Con, 7(2), pp. 59-79.

[13] Ferretti, E., Di Leo, A., \& Viola, E. (2003). Computational aspects and numerical simulations in the elastic constants identification. Problems in Structural Identification and Diagnostics: General Aspects and Applications Book Series: CISM Courses and Lectures, 471, pp. 133-147.

[14] Hess, R. L. (2008). Unreinforced Masonry (URM) Buildings. Prepared for The ShakeOut Scenario: United States Geological Survey Pasadena CA and California Geological Survey Sacramento CA.

[15] Marnetto, R., \& Vari, A. (2015). Linee Guida - Cuciture attive per la muratura: procedura generale per la progettazione, modellazione, calcolo e verifica di edifici in muratura rinforzati con il sistema di cucitura attiva CAM. EDIL CAM Sistemi S.r.l.

[16] Marnetto, R., Vari, A., Marnetto, L., \& Leonori, M. (2014). Conservare l'edilizia in muratura: il sistema CAM - Cuciture attive dei manufatti. Edizioni PREprogetti.

[17] Ponzo FC, Di Cesare A, Nigro D (2011). An update of innovative retrofitting techniques for $\mathrm{R} / \mathrm{C}$ and masonry building: from experimental investigations to practical applications. Ninth Pacific Conference on Earthquake Engineering, Building an Earthquake-Resilient Society, 14-16 April, 2011, Auckland, New Zealand, 8 pp. 